\title{
Chronic Hepatitis B and HIV Coinfection: a Continuing Challenge in the Era of Antiretroviral Therapy
}

\author{
H. Nina Kim ${ }^{1,2}$ (D) \\ Published online: 16 September 2020 \\ (C) The Author(s) 2020
}

\begin{abstract}
Purpose of Review The burden of chronic hepatitis B (HBV) remains disproportionately high among people living with HIV (PLWH) despite the advent of HBV vaccination and HBV-active antiretroviral therapy (ART). This review summarizes new insights and evolving issues in HIV-HBV coinfection.

Recent Findings HBV-HIV coinfection is still a leading cause of cirrhosis, hepatocellular carcinoma (HCC), and liver-related mortality more than a decade after the approval of tenofovir. While tenofovir-based ART has been shown to improve rates of HBV virologic suppression and halt fibrosis progression, the long-term benefits on the prevention of end-stage liver disease or HCC in HIV-HBV coinfection have yet to be convincingly demonstrated in PLWH. Missed opportunities for HBV vaccination persist despite evidence of ongoing risk for HBV infection in this population.

Summary Even as we work towards HBV elimination and functional cure, ongoing efforts should focus on optimizing risk stratification as well as uptake of HBV-active antiviral therapy and HBV immunization in this priority population.
\end{abstract}

Keywords Hepatitis B $\cdot$ Human immune deficiency virus $(\mathrm{HIV}) \cdot$ Coinfection

\section{Introduction}

With an estimated 257 million people living with chronic hepatitis B (HBV) infection in 2015, HBV is the leading cause of cirrhosis, hepatocellular carcinoma (HCC), and liver-related mortality worldwide [1•]. Mortality from chronic viral hepatitis has surpassed deaths from HIV, tuberculosis, and malaria globally, which has prompted the World Health Organization (WHO) to call for the elimination of chronic hepatitis B and C by 2030 [1 1 . The true extent of chronic hepatitis $\mathrm{B}$ infection among people living with HIV (PLWH) is not known given gaps in HBV screening and surveillance in many parts of the world. One systematic review estimated a global

This article is part of the Topical Collection on Hepatitis B

H. Nina Kim

hyangkim@uw.edu

1 Department of Medicine, Division of Allergy \& Infectious Diseases, University of Washington, 325 Ninth Avenue, Box 359930,

Seattle, WA 98104, USA

2 Center for AIDS Research, University of Washington, Seattle, WA, USA prevalence of $7.6 \%$ in PLWH, with substantial regional variation and higher $(11.8 \%)$ prevalence among people who inject drugs [2•]. HIV-HBV coinfection is more common in areas with ongoing perinatal HBV transmission as seen in parts of Asia and Africa [3].

The prevalence of chronic HBV in PLWH far exceeds that of the general population. In contrast to the prevalence of chronic HBV among US households of $0.3 \%$, the prevalence within HIV cohorts in the United States (US) is as high as 8$11 \%$ [4-6]. Overlapping routes of the transmission of HIV and HBV likely account for the disproportionate burden of HBV in PLWH. Susceptible PLWH may also be more likely than those without HIV infection to progress to chronic HBV infection when exposed [7].

Early studies of the natural history of HIV-HBV coinfection demonstrated that coinfected patients were more likely to have unfavorable features and complications of their liver disease compared with $\mathrm{HBV}$-monoinfected patients: greater probability of positive hepatitis $\mathrm{B}$ e antigen, higher HBV viral levels, and greater incidence of cirrhosis and liver-related mortality [7-9]. However, much of these data originated before the era of highly effective HBV-active antiretroviral therapy (ART), and it remains unclear whether these disparities persist in the current ART era. 
In this review of HIV-HBV coinfection, three main topics will be discussed, with an emphasis on recent insights and areas of uncertainty: (1) liver disease progression in HIVHBV coinfection in the current ART era, (2) key strategies for $\mathrm{HBV}$ prevention in this population given the WHO call for HBV elimination, and (3) management questions when caring for HIV-HBV-coinfected patients in current clinical practice.

\section{Role of HBV-Specific Therapy on Liver Disease Progression in the Current ART Era}

The broad efficacy of direct-acting antiviral therapy for chronic hepatitis $\mathrm{C}$ (HCV) has led the way to HIV-infected individuals no longer being considered a special population with regard to $\mathrm{HCV}$-related liver disease $[10,11]$. Whether the same can be said of HIV-HBV-coinfected individuals is debatable. Excess liver-related morbidity and mortality among HIV-HBV-coinfected individuals have continued to be noted in the years following the introduction of HBV-active ART [12-14]. Moreover, unlike HCV, no therapy exists for HBV that provides a sterilizing cure where one can be assured that the virus will never return. HBV eradication is challenging because of the stability of the HBV genome and its incorporation into the hepatocyte nucleus in the form of covalently closed circular (ccc) DNA $[15,16]$. HBV antiviral therapy is therefore not considered curative but rather disease-modifying at this time [17].

HBV polymerase (P protein) shares a high degree of homology to the reverse transcriptase of retroviruses like HIV [18]. Most of the nucleoside/nucleotide inhibitors now approved for hepatitis B treatment were first investigated as antiretroviral therapy for HIV, specifically lamivudine (3TC), adefovir (ADV), tenofovir disoproxil fumarate (TDF), and tenofovir alafenamide (TAF) (Table 1). Another antiviral, entecavir (ETV), can exert enough anti-HIV-1 activity to select for HIV drug-resistant mutations [19]. In the early ART era, 3TC was the only available antiretroviral agent that had any activity against HBV. This HBV monotherapy was eventually noted to result in high cumulative rates of $3 \mathrm{TC}$ HBV resistance- $20-25 \%$ after 1 year to greater than $50 \%$ after 2 years and greater than $90 \%$ after 4 years [20-22]. The limited durability is why $3 \mathrm{TC}$ HBV monotherapy should be avoided in HIV-HBV-coinfected patients [23 ${ }^{\circ}$ and why $3 \mathrm{TC}$ is no longer considered a first-line oral antiviral for HBV infection [24]. Highly effective antiviral therapy for HBV in PLWH was therefore not prevalent until the years following the introduction of tenofovir-based ART in 2001. Tenofovir disoproxil fumarate (TDF) or the newer formulation, tenofovir alafenamide (TAF), is considered first-line HBV therapy for HIV-HBV-coinfected patients due to their high potency and high genetic barrier for resistance (Table 2). For persons with HIV and HBV coinfection, TDF or TAF is preferred over entecavir as the main HBV antiviral, largely due to the dual antiviral activity of these tenofovir preparations against both HBV and HIV.

The inclusion of tenofovir to HBV management has resulted in significant improvements in HBV virologic control among HIV-HBV-coinfected patients on ART [28-30] as well as in the markers of hepatic function among those with decompensated cirrhosis [31]. Fibrosis regression on antiviral therapy has been well described in HBV monoinfection with most individuals demonstrating histologic improvement and $51 \%$ achieving regression of fibrosis after 5 years of sustained HBV suppression [32]. Whether this occurs to same extent in HIV-HBV remains unclear. One series of 167 HIV-HBVcoinfected patients on TDF-containing ART from France with a median follow-up of 60 months suggested that despite control of HBV replication, fibrosis progression was still observed in $17 \%$ of patients [33]. This study and others have demonstrated that stability in fibrosis appears more likely than widespread improvement in HIV-HBV coinfection [34].

While the short-term benefits of antiviral therapy have been noted, the long-term clinical benefits on liver-related morbidity and mortality are not yet fully delineated in HIV-HBV coinfection. The evidence base for the beneficial impact of antiviral therapy in reducing the risk of adverse clinical outcomes, mainly hepatic decompensation and $\mathrm{HCC}$, is stronger

Table 1 Oral nucleoside or nucleotide analogue therapy with activity against hepatitis B and full/partial activity against HIV

\begin{tabular}{lllll}
\hline Medication & $\begin{array}{l}\text { Potency } \\
\text { against HBV }\end{array}$ & $\begin{array}{l}\text { Barrier to HBV } \\
\text { Resistance }\end{array}$ & HIV Activity & $\begin{array}{l}\text { Selection of HIV } \\
\text { Resistance Reported }\end{array}$ \\
\hline Lamivudine & Moderate & Low & Yes & Yes \\
Adefovir & Low & Moderate & No & No \\
Entecavir & High & High & Yartial & Yes \\
Emtricitabine & Moderate & Low & Partial & Yes \\
Telbivudine & High & Low & Yes & No \\
Tenofovir (AF or DF) & High & High & Yes & \\
\hline
\end{tabular}

${ }^{a}$ Anti-HIV activity at higher doses; more potent against HBV

${ }^{\mathrm{b}}$ Preferred therapy for chronic hepatitis B infection in HBV monoinfection 
Table 2 Summary of recommendations for HBV-specific antiviral therapy in persons living with HIV and chronic hepatitis B

\begin{tabular}{|c|c|c|}
\hline Guidelines & When to initiate & What to initiate \\
\hline AASLD HBV 2018 update [25] & $\begin{array}{l}\text { All HIV-HBV patients, } \\
\text { regardless of CD4 cell count }\end{array}$ & $\begin{array}{l}\text { Two HBV-active agents: tenofovir (TAF or TDF) } \\
\text { with lamivudine or emtricitabine }\end{array}$ \\
\hline DHHS OI, 2019 [23•] & $\begin{array}{l}\text { All HIV-HBV patients, } \\
\text { regardless of CD4 cell count }\end{array}$ & $\begin{array}{l}\text { Tenofovir (TAF or TDF) with emtricitabine; } \\
\text { chronic administration of lamivudine or } \\
\text { emtricitabine as the only HBV-active agent } \\
\text { as part of ART should be avoided. }\end{array}$ \\
\hline EASL HBV, 2017 [26] & $\begin{array}{l}\text { All HIV-HBV patients, } \\
\text { regardless of CD4 cell count }\end{array}$ & Tenofovir (TAF or TDF) containing ART regimen \\
\hline APASL HBV, 2015 [27] & $\begin{array}{l}\text { All HIV-HBV patients, "irrespective of } \\
\text { immunological, virological or } \\
\text { histological considerations" }\end{array}$ & $\begin{array}{l}\text { Two HBV-active agents: tenofovir } \\
\text { with lamivudine or emtricitabine }\end{array}$ \\
\hline
\end{tabular}

AASLD American Association for the Study of Liver Diseases, $H B V$ hepatitis B, $T A F$ tenofovir alafenamide, $T D F$ tenofovir disoproxil fumarate, $D H H S$ US Department of Health \& Human Services, OI opportunistic infections, EASL European Association for the Study of Liver, APASL Asian Pacific Association for the Study of the Liver

in HBV monoinfection, particularly in patients with cirrhosis $[35,36]$. One of the largest longitudinal cohort studies evaluated 3573 individuals with HIV-HBV coinfection from ten clinical cohorts in the North American AIDS Cohort Collaboration from 1996 to 2010 and examined validated end points of end-stage liver disease (ESLD) and HCC [37•]. During follow-up, 111 (3\%) developed liver complication (90 with ESLD, 11 with HCC, and 10 with both) with an incidence rate of 8 events per 1000 person-years that did not significantly differ when stratified by early (1996-2001) versus later (2002-2010) ART eras (Fig. 1). Higher baseline Fibrosis-4 (FIB-4) score, lower CD4 cell count, and diabetes mellitus were associated with greater risk of liver complications during follow-up. Sustained HIV suppression $(\geq$ 6 months) appeared to be protective and associated with a lower risk of ESLD/HCC with an adjusted hazard ratio (aHR) of 0.56 (95\% confidence interval, 0.35-0.91). The risk of liver complications was also lower for those on HBV-active ART and particularly for regimens that included tenofovir, but results were not statistically significant (aHR 0.36, 95\% CI 0.12 to 1.03 ). This may have been due to the limited duration of follow-up in this study as well as some gaps in tenofovir coverage in this cohort.

Another large population-based study in the current ART era examined differences in clinical outcomes for chronic hepatitis B among those with and without HIV from a centralized database of hospital billing claims in metropolitan France from 2008 to 2013 [38]. The primary outcome was liver disease progression defined as a composite outcome of ESLD or HCC before liver transplantation or death. Among 48,189 patients with chronic HBV, 5757 (12\%) were HIV coinfected. Liver disease progression was documented in $15.5 \%$ and associated with older age and male gender. Despite having a higher prevalence of risk factors associated with liver disease (i.e., HCV coinfection, diabetes), HIV-HBV-coinfected patients were less likely to experience liver disease progression
(aHR 0.77 , 95\% CI 0.71 to 0.83 ) than patients with HBV alone, with a lower risk observed especially in those without an AIDS diagnosis at that time. The authors postulated that the more widespread use of HBV treatment among PLWH on ART likely accounted for this protective effect but antiviral therapy was not captured in this study. A Dutch study however did capture antiviral therapy and found no significant difference in time to ESLD or all-cause death when comparing HIV-HBV-coinfected to HBV monoinfected individuals from 2003 to 2015 [39]. The findings from this study need to be interpreted with caution due to the substantial difference in follow-up between monoinfected and coinfected cohorts (median 3.8 vs 10.3 years with attrition of $40 \%$ vs $12 \%$ respectively).

In summary, we need further research to explore the longterm impact of first-line HBV antiviral therapy on liver disease progression and liver-related mortality in the context of HIV-HBV coinfection.

\section{HBV Prevention with the Goal of Elimination}

$\mathrm{HBV}$ vaccination remains the cornerstone of $\mathrm{HBV}$ prevention and ultimately the core intervention in the global effort to eliminate HBV by 2030. Universal HBV vaccination is recommended for all infants, as well as all unvaccinated children and adolescents [40•]. For adults, the HBV vaccine should be given to all persons at risk of acquiring HBV including persons living with HIV. The introduction of HBV vaccination in 1980s resulted in a $70 \%$ decline in HBV infections in the US but no further reduction in the prevalence of persons with chronic HBV [6, 41]. In the Multicenter AIDS Cohort Study, a longitudinal cohort of men who have sex with men in the US, incident HBV infection was nearly 2-fold higher in HIV-infected MSM compared with HIV-uninfected MSM and ART was not found to be completely protective [42]. 


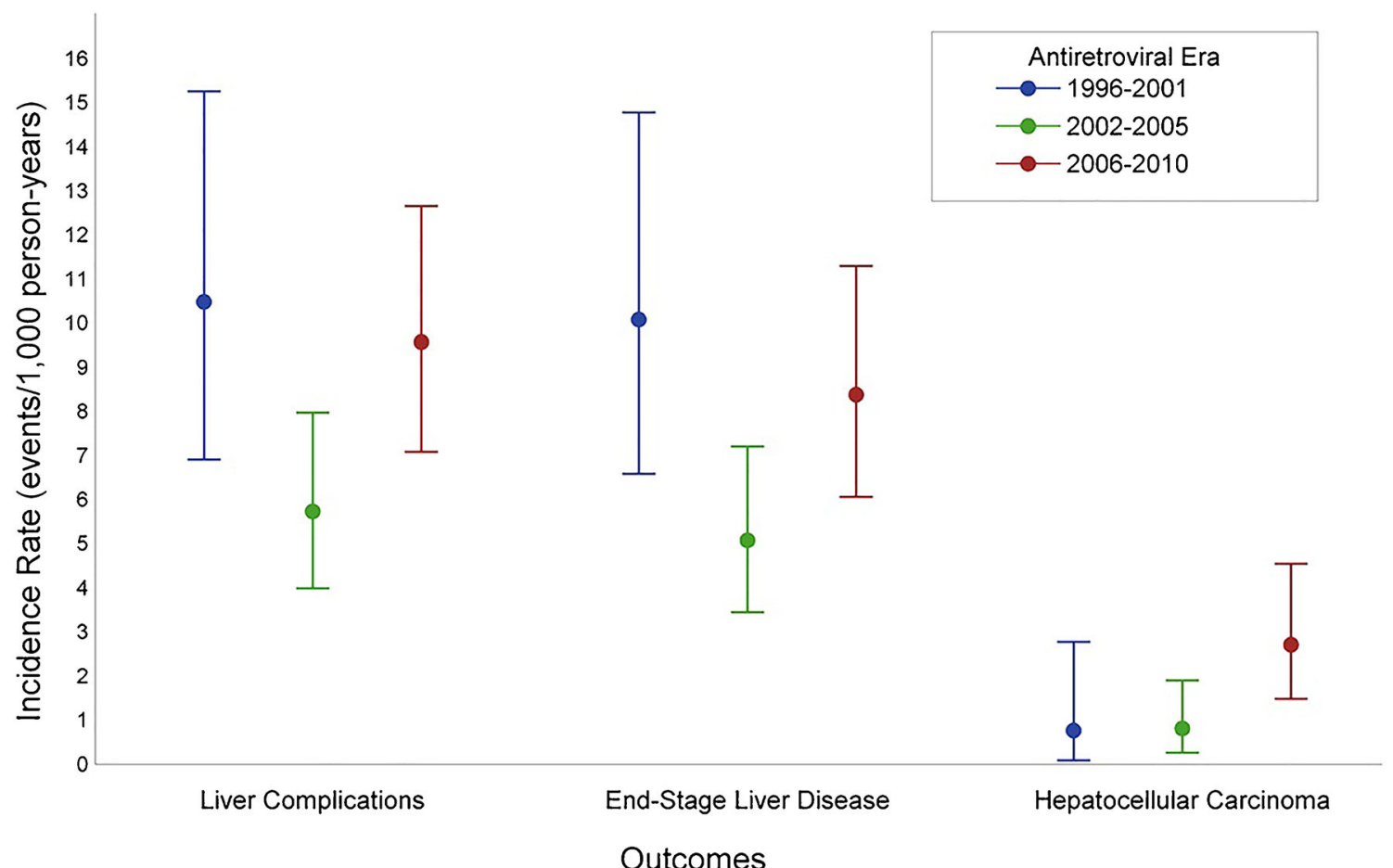

Fig. 1 Incidence rates and 95\% confidence intervals of liver complications (composite of first occurrence of ESLD or HCC diagnosis), ESLD, and HCC among HIV/HBV-coinfected patients in the North American AIDS Cohort Collaboration on Research and

Nationally in the US, rates of HBV have risen in regions where opioid use has been prevalent [43]. HBV incidence has also been shown to be moderately high in HBV-endemic settings among PLWH with relatively preserved CD4 cell counts [44]. HBV burden is also higher among marginalized populations such as those who inject drugs or are imprisoned, who are also at greater risk of HIV $[2,45]$.

Unfortunately, despite recommendations to immunize all susceptible persons with HIV against hepatitis B, one study conducted by the US Centers for Disease Control of over 18,000 patients in HIV care from 2009 to 2012 found that $44.2 \%$ had no documentation of HBV vaccination, immunity or infection in the medical record [46॰]. Among those who were eligible for vaccination, only $9.6 \%$ were immunized and $7.5 \%$ were found to have new documentation of HBV immunity or infection during the 1-year surveillance period. The prevalence of vaccination was low regardless of clinical or sociodemographic characteristics and particularly low in clinics not supported by Ryan White funding. Notably, this study also identified gaps in ART coverage active against both HIV and HBV with only $65 \%$ receiving tenofovir-based ART. A number of barriers probably contributed to these poor immunization rates, including a history of inconsistent recommendations regarding timing of $\mathrm{HBV}$ immunization in PLWH and reports of reduced immunogenicity in PLWH. The lack of robust health systems that enable affordable access to adult immunization also likely posed challenges [47].
Design (January 1996-December 2010), by antiretroviral therapy era (1996-2001, 2002-2005, 2006-2010). Source: JAIDS Journal of Acquired Immune Deficiency Syndromes82(1):71-80, September 1, 2019

The US guidelines for the prevention and treatment of opportunistic infections (OI) in HIV acknowledge that patients with lower CD4 cell counts or ongoing HIV viral replication may not achieve seroprotection as often as those with preserved immune status and effective HIV suppression but emphasize that HBV immunization should not be deferred due to concern for lack of response [23•]. This is particularly so for patients at high risk for HBV acquisition or adverse sequelae from HBV infection, such as men who have sex with men, people who inject drugs, and those with HCV coinfection. HBV-active ART may provide some level of HBV preexposure prophylaxis for patients who are susceptible [48], but this is not failsafe [42] or the preferred strategy for preventing HBV. All efforts should be made to initiate and complete immunization in susceptible PLWH and assess for seroprotection with hepatitis B surface antibody 1 month after completion.

A variety of strategies including revaccination with doubledose recombinant HBV vaccine have been studied in HIVinfected non-responders [49], but there is no current consensus on the best revaccination strategy. The essential point is that regardless of how, revaccination should be attempted as $44 \%$ or more of non-responders can seroconvert with a second HBV vaccine series [23•].

In November 2017, a novel hepatitis B vaccine, HepBCpG (Heplisav-B), was approved by the US Food \& Drug Administration. Like the alum-adjuvanted vaccines 
(Recombivax or Engerix-B) that have been the standard of care, HepB-CpG contains the yeast-derived recombinant hepatitis B surface antigen but is adjuvanted instead with a cytidine phosphoguanosine $(\mathrm{CpG})$ oligonucleotide which binds to toll-like receptor 9 and signals an innate immune system pathway response. Three phase 3 registration trials were conducted that together enrolled 9597 adults aged 18-70 years to receive HepB-CpG in two doses, spaced 1 month apart with a saline placebo for the final dose compared with standard 3dose hepatitis B vaccine (Engerix-B) [50-52]. The overall seroprotection rate (SPR) induced by HepB-CpG was higher in the range of 90-100\% compared with 71-90\% for Engerix$B$ with a difference in SPR ranging from 6\% for 18-29-yearolds to $19 \%$ for 60-70-year-olds. A significant improvement in SPR was also noted for important subpopulations, namely patients with diabetes, tobacco use, or obesity. Whether this efficacy is also seen in PLWH remains to be shown. HepB$\mathrm{CpG}$ is not currently approved for PLWH. The OI guidelines simply note this as an alternate option with limited evidence if a 2-dose strategy is preferred [23•]. The safety and efficacy of HepB-CpG are currently being studied through the clinical trial, B-Enhancement of HBV Vaccination in Persons Living With HIV (BeE-HIVE).

\section{Management Issues: Functional Cure, Fibrosis Assessment, and Hepatocellular Carcinoma}

\section{Hepatitis B Surface Antigen Loss and Functional Cure}

The loss of hepatitis B surface antigen (HBsAg), either spontaneously or with antiviral therapy, does not necessarily indicate HBV eradication, but it remains the ultimate serologic goal for antiviral therapy. Seroclearance of HBsAg (with or without seroconversion to hepatitis B surface antibody) is the consensus definition of a "functional cure" in patients with chronic HBV and an elusive goal at this time [53]. HBsAg seroclearance is a rare event in most individuals (treated or untreated) with chronic HBV. One meta-analysis of 34 published studies estimated the pooled annual rate to be $1 \%$ with a cumulative 5-year rate of $4 \%$ with a higher likelihood of clearance noted in those with lower HBV DNA levels or with HBe antigen negative status at baseline [54]. Additional strategies are needed to achieve higher and more consistent rates of functional cure in persons with chronic HBV with or without HIV as HBsAg loss has been shown to be associated with improved clinical outcomes $[53,55]$. Chronic HBV poses a variety of challenges to reaching this goal apart from HBV DNA integration. Immune exhaustion and dysregulation, as well as inhibitory pathways suppressing the immune response, can also contribute to persistence of HBV infection [56].

The spectrum of functional cure, or HBsAg seroclearance, in individuals with HIV-HBV coinfection is not well understood. Some studies have suggested that the rate of HBsAg seroclearance with treatment may be higher in coinfection compared with monoinfection [57-59], but this has not been studied rigorously or observed universally across HIV cohorts [60]. One of the larger HIV-HBV cohort studies that examined this from Zambia reported a HBsAg seroclearance rate of $10.2 \%$ within 2 years of tenofovir-based ART initiation [59]. In multivariable analysis, in addition to female sex and lower HBV viral levels, lower pre-therapy CD4 cell count $(<$ 350 cells $/ \mathrm{mm}^{3}$ ) was independently associated with greater odds of clearance. Another study of 173 coinfected patients from the Netherlands found comparable results and noted that quantitative HBsAg levels were significantly lower in patients who had a more robust CD4 cell recovery on ART [61]. These and other studies $[58,62]$ highlight the key role of ART-initiated immune restoration in $\mathrm{HBsAg}$ seroclearance.

What implications these findings have for our clinical practice is not known, particularly given that true functional cure implies sustained HBsAg loss after cessation of antiviral therapy which would not generally be advised or practicable in HIV-HBV-coinfected individuals. However, these studies highlight the dynamic nature of HBV immunologic control in those with HIV and may offer insights in our search for a functional cure. At the very least, they suggest that we should be checking for HBsAg clearance more consistently in our coinfected patients, particularly during the first few years of therapy when changes are most likely to occur.

\section{Fibrosis Assessment}

The decision-making around whether or not to start HBVactive antiviral therapy is much simpler in PLWH than in HBV monoinfected patients because of the current recommendation to start ART in all PLWH regardless of their CD4 cell count or viral hepatitis status [63] and because treatment of HIV would generally entail concurrent treatment of HBV. This universal ART recommendation however has effectively obviated the motivation to conduct risk stratification in HIVHBV coinfection which can include regular assessment of HBV serologic tests or fibrosis staging. Of these, fibrosis staging is particularly critical in the optimal management of patients with HIV-HBV coinfection because the severity of fibrosis and presence of cirrhosis are among the strongest predictors of liver-related complications, particularly HCC.

Cirrhosis, as a histologic diagnosis, is often underrecognized in routine clinical practice [64]. Standard imaging and laboratory assessments are not sufficiently sensitive or specific and can often miss detection of patients with advanced fibrosis. Liver biopsy is the imperfect gold standard for assessing cirrhosis, and while the risk of complications such as intrahepatic bleeding or biliary injury is very low, it is invasive and therefore recommended in only a subset of patients with chronic hepatitis B [65]. 
In the absence of biopsy, serum biomarkers could be potentially useful. The FIB-4 index was first validated in HIV and hepatitis $\mathrm{C}$ coinfected patients and has been shown to have reasonable performance in differentiating mild (stage 0-1) from more advanced (stage 3-4) fibrosis in chronic hepatitis B [66]. However, the utility and predictive values of FIB-4, as well as AST-platelet ratio index (APRI), are limited in patients on antiviral therapy as suggested by one study that noted substantial misclassification in $575 \mathrm{HBV}$-monoinfected patients on tenofovir who had baseline liver biopsies as well as FIB-4 and APRI measurements [67]. An overwhelming majority (81-89\%) of patients with advanced fibrosis or cirrhosis were missed when using these scores.

Transient elastography (VCTE) may prove to be a better tool for detecting advanced fibrosis in HIV-HBV-coinfected patients on ART. Investigators from the Hepatitis B Research Network evaluated 108 coinfected patients (99\% of whom were on HBV-active ART) and found that, when using liver stiffness measurement cutoffs of $5.0 \mathrm{kPa}$ to exclude and $8.8 \mathrm{kPa}$ to confirm advanced fibrosis, VCTE had an areaunder-the-receiver-operating curve of 0.87 compared with 0.66 for FIB-4 or 0.69 for APRI [68]. More evidence is needed to validate these findings in other settings.

\section{Hepatocellular Carcinoma}

As the population of PLWH has grown and aged in the ART era, HCC has emerged as a leading non-AIDS-related cancer [69]. HCC incidence and attributable mortality have increased across multiple HIV cohorts in US and Canada in the ART era $[70,71]$. PLWH may be at greater risk for not only HCC but a poor prognosis with HCC compared with HIV-uninfected persons. Observational studies (that often include a mix of HBVand $\mathrm{HCV}$-associated $\mathrm{HCC}$ ) have noted a more aggressive course of HCC in PLWH with younger age at diagnosis, extrahepatic disease, and shorter survival $[72,73]$. One large study from the Veterans Administration, of which HIVHBV-coinfected individuals comprised 5.6\%, noted that poorly controlled HIV infection (as manifested by lower CD4 cell counts, higher HIV viral levels, or longer periods of detectable HIV) was associated with greater risk of HCC [74].

Ultimately, most of our knowledge of HBV-associated HCC originates from native Asian cohorts without HIV infection [75]. Few studies have examined HCC specifically in PLWH with chronic HBV. Moreover, we lack direct evidence for the effectiveness of HCC screening in HIV-HBV coinfection. Ultrasound surveillance has been adopted as standard practice in resource-rich settings, but it remains unclear whether this modality is adequate for detecting early-stage tumors amenable to curative ablative therapy in PLWH or whether this has made a clinically meaningful difference in survival [76]. The existing data on the adverse impact on HIVassociated immunosuppression on carcinogenesis and tumor progression would suggest that we need to examine our current practices more rigorously. Identification of optimal strategies for preventing and managing $\mathrm{HCC}$ is urgently needed in this priority population.

\section{Conclusion}

Despite advances in HBV prevention and care in the past few decades, HIV-HBV coinfection remains a significant contributor to non-AIDS-related death and liver-related complications. There have been missed opportunities around HBV screening, HBV immunization, and the use of tenofovirbased ART in all HIV-HBV-coinfected individuals. Achievements in HCV therapy have renewed scientific interest in a functional HBV cure, but until this is attained, future efforts should be directed at refining risk stratification to identify those most vulnerable to HBV-related complications and should focus on implementation science around how best to bridge gaps in clinical practice.

\section{Compliance with Ethical Standards}

Conflict of Interest None.

Human and Animal Rights and Informed Consent This article does not contain any studies with human or animal subjects performed by any of the authors.

Open Access This article is licensed under a Creative Commons Attribution 4.0 International License, which permits use, sharing, adaptation, distribution and reproduction in any medium or format, as long as you give appropriate credit to the original author(s) and the source, provide a link to the Creative Commons licence, and indicate if changes were made. The images or other third party material in this article are included in the article's Creative Commons licence, unless indicated otherwise in a credit line to the material. If material is not included in the article's Creative Commons licence and your intended use is not permitted by statutory regulation or exceeds the permitted use, you will need to obtain permission directly from the copyright holder. To view a copy of this licence, visit http://creativecommons.org/licenses/by/4.0/.

\section{References}

Papers of particular interest, published recently, have been highlighted as:

\section{- Of importance}

1. World Health Organization. Global hepatitis report, 2017. https:// www.who.int/publications-detail-redirect/global-hepatitis-report2017 (accessed Jul 1, 2020). This landmark report describes, for the first time, how viral hepatitis has emerged as a major public health threat globally and why a coordinated response is urgently needed. 
2. Platt L, French CE, McGowan CR, Sabin K, Gower E, Trickey A, et al. Prevalence and burden of HBV co-infection among people living with HIV: a global systematic review and meta-analysis. J Viral Hepat. 2020;27:294-315. https://doi.org/10.1111/jvh.13217 This major systematic review provides regional and country estimates of the prevalence of chronic hepatitis B among PLWH across multiple subpopulations of interest.

3. Kourtis AP, Bulterys M, Hu DJ, Jamieson DJ. HIV-HBV coinfection-a global challenge. N Engl J Med. 2012;366:174952. https://doi.org/10.1056/NEJMp1201796.

4. Chun HM, Fieberg AM, Hullsiek KH, Lifson AR, Crum-Cianflone NF, Weintrob AC, et al. Epidemiology of hepatitis B virus infection in a US cohort of HIV-infected individuals during the past 20 years. Clin Infect Dis. 2010;50:426-36. https://doi.org/10.1086/649885.

5. Spradling PR, Richardson JT, Buchacz K, Moorman AC, Brooks JT, HIV Outpatient Study (HOPS) Investigators. Prevalence of chronic hepatitis B virus infection among patients in the HIV Outpatient Study, 1996-2007. J Viral Hepat. 2010;17:879-86. https://doi.org/10.1111/j.1365-2893.2009.01249.x.

6. Roberts H, Kruszon-Moran D, Ly KN, Hughes E, Iqbal K, Jiles $\mathrm{RB}$, et al. Prevalence of chronic hepatitis $\mathrm{B}$ virus (HBV) infection in U.S. households: National Health and Nutrition Examination Survey (NHANES), 1988-2012. Hepatology. 2016;63:388-97. https://doi.org/10.1002/hep.28109.

7. Puoti M, Torti C, Bruno R, Filice G, Carosi G. Natural history of chronic hepatitis B in co-infected patients. J Hepatol. 2006;44:S6570. https://doi.org/10.1016/j.jhep.2005.11.015.

8. Colin JF, Cazals-Hatem D, Loriot MA, Martinot-Peignoux M, Pham BN, Auperin A, et al. Influence of human immunodeficiency virus infection on chronic hepatitis B in homosexual men. Hepatology. 1999;29:1306-10. https://doi.org/10.1002/hep. 510290447.

9. Thio CL, Seaberg EC, Skolasky R, Phair J, Visscher B, Muñoz A, et al. HIV-1, hepatitis B virus, and risk of liver-related mortality in the Multicenter Cohort Study (MACS). Lancet. 2002;360:1921-6. https://doi.org/10.1016/s0140-6736(02)11913-1.

10. Sikavi C, Chen PH, Lee AD, Saab EG, Choi G, Saab S. Hepatitis C and human immunodeficiency virus coinfection in the era of directacting antiviral agents: no longer a difficult-to-treat population. Hepatology. 2018;67:847-57. https://doi.org/10.1002/hep.29642.

11. AASLD/IDSA. Patients with HIV/HCV coinfection. Recommendations for testing, managing, and treating hepatitis C. https://www.hcvguidelines.org/unique-populations/hiv-hov (accessed Jul 2, 2020).

12. Falade-Nwulia O, Seaberg EC, Rinaldo CR, Badri S, Witt M, Thio CL. Comparative risk of liver-related mortality from chronic hepatitis $\mathrm{B}$ versus chronic hepatitis $\mathrm{C}$ virus infection. Clin Infect Dis. 2012;55:507-13. https://doi.org/10.1093/cid/cis432.

13. Klein MB, Althoff KN, Jing Y, Lau B, Kitahata M, Lo Re V, et al. Risk of end-stage liver disease in HIV-viral hepatitis coinfected persons in North America from the early to modern antiretroviral therapy eras. Clin Infect Dis. 2016;63:1160-7. https://doi.org/10. 1093/cid/ciw531.

14. Thornton AC, Jose S, Bhagani S, Chadwick D, Dunn D, Gilson R, et al. Hepatitis B, hepatitis C, and mortality among HIV-positive individuals. AIDS. 2017;31:2525-32. https://doi.org/10.1097/ QAD.0000000000001646.

15. Dienstag JL. Hepatitis B virus infection. N Engl J Med. 2008;359: 1486-500. https://doi.org/10.1056/NEJMra0801644.

16. Tu T, Budzinska MA, Shackel NA, Urban S. HBV DNA Integration: molecular mechanisms and clinical implications. Viruses. 2017;9. https://doi.org/10.3390/v9040075.

17. Likhitsup A, Lok AS. Understanding the natural history of hepatitis $B$ virus infection and the new definitions of cure and the endpoints of clinical trials. Clin Liver Dis. 2019;23:401-16. https://doi.org/ 10.1016/j.cld.2019.04.002.
18. Robinson WS, Miller RH, Marion PL. Hepadnaviruses and retroviruses share genome homology and features of replication. Hepatology. 1987;7:64S-73S. https://doi.org/10.1002/hep. 1840070712.

19. McMahon MA, Jilek BL, Brennan TP, Shen L, Zhou Y, WindRotolo M, et al. The HBV drug entecavir - effects on HIV-1 replication and resistance. N Engl J Med. 2007;356:2614-21. https:// doi.org/10.1056/NEJMoa067710.

20. Benhamou Y, Bochet M, Thibault V, Di Martino V, Caumes E, Bricaire $\mathrm{F}$, et al. Long-term incidence of hepatitis $\mathrm{B}$ virus resistance to lamivudine in human immunodeficiency virus-infected patients. Hepatology. 1999;30:1302-6. https://doi.org/10.1002/hep. 510300525.

21. Wolters LMM, Niesters HGM, Hansen BE, van der Ende ME, Kroon FP, Richter C, et al. Development of hepatitis B virus resistance for lamivudine in chronic hepatitis B patients co-infected with the human immunodeficiency virus in a Dutch cohort. J Clin Virol. 2002;24:173-81. https://doi.org/10.1016/s1386-6532(01)00245-1.

22. Matthews GV, Bartholomeusz A, Locarnini S, Ayres A, Sasaduesz $\mathrm{J}$, Seaberg E, et al. Characteristics of drug resistant HBV in an international collaborative study of HIV-HBV-infected individuals on extended lamivudine therapy. AIDS. 2006;20:863-70. https:// doi.org/10.1097/01.aids.0000218550.85081.59.

23. Panel on Guidelines for the Prevention and Treatment of Opportunistic Infections in Adults and Adolescents with HIV. Guidelines for the prevention and treatment of opportunistic infections in HIV-infected adults and adolescents: recommendations from the Centers for Disease Control and Prevention, the National Institutes of Health, and the HIV Medicine Association of the Infectious Diseases Society of America. 2020. http:// aidsinfo.nih.gov/contentfiles/lvguidelines/adult oi.pdf. Accessed 2 July 2020. Important evidence-based guidelines on a variety of coinfections including $\mathrm{HBV}$, aimed at clinicians involved in the care of PLWH.

24. Lok ASF, McMahon BJ, Practice Guidelines Committee, American Association for the Study of Liver Diseases (AASLD). Chronic hepatitis B: update of recommendations. Hepatology. 2004;39: 857-61. https://doi.org/10.1002/hep.20110.

25. Terrault NA, Lok ASF, McMahon BJ, Chang K-M, Hwang JP, Jonas MM, et al. Update on prevention, diagnosis, and treatment of chronic hepatitis B: AASLD 2018 hepatitis B guidance. Hepatol. 2018;67:1560-99. https://doi.org/10.1002/hep.29800.

26. European Association for the Study of the Liver. EASL 2017 clinical practice guidelines on the management of hepatitis B virus infection. J Hepatol. 2017;67:370-98. https://doi.org/10.1016/j. jhep.2017.03.021.

27. Sarin SK, Kumar M, Lau GK, Abbas Z, Chan HLY, Chen CJ, et al. Asian-Pacific clinical practice guidelines on the management of hepatitis B: a 2015 update. Hepatol International. 2016;10:1-98. https://doi.org/10.1007/s12072-015-9675-4.

28. Matthews GV, Seaberg E, Dore GJ, Bowden S, Lewin SR, Sasadeusz J, et al. Combination HBV therapy is linked to greater HBV DNA suppression in a cohort of lamivudine-experienced HIV/HBV coinfected individuals. AIDS. 2009;23:1707-15. https://doi.org/10.1097/QAD.0b013e32832b43f2.

29. de Vries-Sluijs TEMS, Reijnders JGP, Hansen BE, Zaaijer HL, Prins JM, Pas SD, et al. Long-term therapy with tenofovir is effective for patients co-infected with human immunodeficiency virus and hepatitis B virus. Gastroenterology. 2010;139:1934 41. https:// doi.org/10.1053/j.gastro.2010.08.045.

30. Price H, Dunn D, Pillay D, Bani-Sadr F, de Vries-Sluijs T, Jain MK, et al. Suppression of HBV by tenofovir in HBV/HIV coinfected patients: a systematic review and meta-analysis. PLOS ONE. 2013;8:e68152. https://doi.org/10.1371/journal.pone.0068152. 
31. Matthews GV, Cooper DA, Dore GJ. Improvements in parameters of end-stage liver disease in patients with HIV/HBV-related cirrhosis treated with tenofovir. Antivir Ther (Lond). 2007;12:119-22.

32. Marcellin P, Gane E, Buti M, Afdhal N, Sievert W, Jacobson IM, et al. Regression of cirrhosis during treatment with tenofovir disoproxil fumarate for chronic hepatitis B: a 5-year open-label follow-up study. Lancet. 2013;381:468-75. https://doi.org/10. 1016/S0140-6736(12)61425-1.

33. Boyd A, Bottero J, Miailhes P, Lascoux-Combe C, Rougier H, Girard P-M, et al. Liver fibrosis regression and progression during controlled hepatitis B virus infection among HIV-HBV patients treated with tenofovir disoproxil fumarate in France: a prospective cohort study. J Int AIDS Soc. 2017;20:21426. https://doi.org/10. 7448/IAS.20.1.21426.

34. Martín-Carbonero L, Teixeira T, Poveda E, Plaza Z, Vispo E, González-Lahoz J, et al. Clinical and virological outcomes in HIV-infected patients with chronic hepatitis B on long-term nucleos(t)ide analogues. AIDS. 2011;25:73-9. https://doi.org/10. 1097/QAD.0b013e328340fde2.

35. Papatheodoridis GV, Idilman R, Dalekos GN, Buti M, Chi H, van Boemmel F, et al. The risk of hepatocellular carcinoma decreases after the first 5 years of entecavir or tenofovir in Caucasians with chronic hepatitis B. Hepatology. 2017;66:1444-53. https://doi.org/ 10.1002/hep.29320.

36. Lok ASF, McMahon BJ, Brown RS, Wong JB, Ahmed AT, Farah $\mathrm{W}$, et al. Antiviral therapy for chronic hepatitis B viral infection in adults: a systematic review and meta-analysis. Hepatology. 2016;63:284-306. https://doi.org/10.1002/hep.28280.

37. Lo Re V, Newcomb CW, Carbonari DM, Roy JA, Althoff KN, Kitahata MM, et al. Determinants of liver complications among $\mathrm{HIV} /$ hepatitis B virus-coinfected patients. J Acquir Immune Defic Syndr. 2019;82:71-80. https://doi.org/10.1097/QAI. 0000000000002094 One of the larger observational studies examining factors associated with ESLD and HCC specifically in HIV-HBV coinfection in the contemporary ART era; the strength of study is the use of validated clinical end points.

38. Mallet V, Hamed K, Schwarzinger M. Prognosis of patients with chronic hepatitis B in France (2008-2013): a nationwide, observational and hospital-based study. J Hepatol. 2017;66:514-20. https:// doi.org/10.1016/j.jhep.2016.10.031.

39. Lieveld FI, Smit C, Richter C, van Erpecum KJ, Spanier BWM, Gisolf EH, et al. Liver decompensation in HIV/hepatitis B coinfection in the combination antiretroviral therapy era does not seem increased compared to hepatitis B mono-infection. Liver Int. 2019;39:470-83. https://doi.org/10.1111/liv.14000.

40. Schillie S, Vellozzi C, Reingold A, Harris A, Haber P, Ward JW, et al. Prevention of hepatitis B virus infection in the United States: recommendations of the Advisory Committee on Immunization Practices. MMWR Recomm Rep. 2018;67:1-31. https://doi.org/ 10.15585/mmwr.rr6701a1 This important report summarizes the current landscape of chronic $\mathrm{HBV}$ in the US, and updates recommendations around $\mathrm{HBV}$ prevention from the Advisory Committee on Immunization Practices and CDC.

41. Centers of Disease Control. U.S. 2017 Surveillance data for viral hepatitis | CDC 2019. http://www.cdc.gov/hepatitis/statistics/ 2017surveillance/index.htm (accessed Jun 29, 2020).

42. Falade-Nwulia O, Seaberg EC, Snider AE, Rinaldo CR, Phair J, Witt MD, et al. Incident hepatitis B virus infection in HIV-infected and HIV-uninfected men who have sex with men from pre-HAART to HAART periods: a cohort study. Ann Intern Med. 2015;163: 673-80. https://doi.org/10.7326/M15-0547.

43. Kushner T, Chen Z, Tressler S, Kaufman H, Feinberg J, Terrault NA. Trends in hepatitis B infection and immunity among women of childbearing age in the United States. Clin Infect Dis. 2019;71:58692. https://doi.org/10.1093/cid/ciz841.
44. Phinius BB, Anderson M, Bokete R, Mbangiwa T, Choga WT, Baruti K, et al. Incidence of hepatitis B virus infection among human immunodeficiency virus-infected treatment naïve adults in Botswana. Medicine (Baltimore). 2020;99:e19341. https://doi.org/ 10.1097/MD.0000000000019341.

45. Wirtz AL, Yeh PT, Flath NL, Beyrer C, Dolan K. HIV and viral hepatitis among imprisoned key populations. Epidemiol Rev. 2018;40:12-26. https://doi.org/10.1093/epirev/mxy003.

46. Weiser J, Perez A, Bradley H, King H, Shouse RL. Low prevalence of hepatitis B vaccination among patients receiving medical care for HIV infection in the United States, 2009 to 2012. Ann Intern Med. 2018;168:245-54. https://doi.org/10.7326/M17-1689 A critical analysis of HBV vaccination practices from CDC's Medical Monitoring Project, a surveillance system that aims to provide nationally representative, cross-sectional estimates of behavioral and clinical characteristics of HIV-positive adults in the US.

47. Abara WE, Qaseem A, Schillie S, McMahon BJ, Harris AM, High Value Care Task Force of the American College of Physicians and the Centers for Disease Control and Prevention. Hepatitis B vaccination, screening, and linkage to care: best practice advice from the American College of Physicians and the Centers for Disease Control and Prevention. Ann Intern Med. 2017;167:794-804. https://doi.org/10.7326/M17-1106.

48. Shilaih M, Marzel A, Scherrer AU, Braun DL, Kovari H, Rougemont M, et al. Dually active HIV/HBV antiretrovirals as protection against incident hepatitis B infections: potential for prophylaxis. J Infect Dis. 2016;214:599-606. https://doi.org/10.1093/ infdis/jiw195.

49. Lee J-H, Hong S, Im JH, Lee J-S, Baek JH, Kwon HY. Systematic review and meta-analysis of immune response of double dose of hepatitis B vaccination in HIV-infected patients. Vaccine. 2020;38: 3995-4000. https://doi.org/10.1016/j.vaccine.2020.04.022.

50. Halperin SA, Ward B, Cooper C, Predy G, Diaz-Mitoma F, Dionne $\mathrm{M}$, et al. Comparison of safety and immunogenicity of two doses of investigational hepatitis B virus surface antigen co-administered with an immunostimulatory phosphorothioate oligodeoxyribonucleotide and three doses of a licensed hepatitis B vaccine in healthy adults $18-55$ years of age. Vaccine. 2012;30: 2556-63. https://doi.org/10.1016/j.vaccine.2012.01.087.

51. Janssen JM, Jackson S, Heyward WL, Janssen RS. Immunogenicity of an investigational hepatitis $\mathrm{B}$ vaccine with a toll-like receptor 9 agonist adjuvant (HBsAg-1018) compared with a licensed hepatitis B vaccine in subpopulations of healthy adults 18-70 years of age. Vaccine. 2015;33:3614-8. https://doi.org/10. 1016/j.vaccine.2015.05.070.

52. Jackson S, Lentino J, Kopp J, Murray L, Ellison W, Rhee M, et al. Immunogenicity of a two-dose investigational hepatitis B vaccine, HBsAg-1018, using a toll-like receptor 9 agonist adjuvant compared with a licensed hepatitis B vaccine in adults. Vaccine. 2018;36:668-74. https://doi.org/10.1016/j.vaccine.2017.12.038.

53. Yip TC-F, Lok AS-F. How do we determine whether a functional cure for HBV infection has been achieved? Clin Gastroenterol Hepatol. 2020;18:548-50. https://doi.org/10.1016/j.cgh.2019.08. 033.

54. Yeo YH, Ho HJ, Yang H-I, Tseng T-C, Hosaka T, Trinh HN, et al. Factors associated with rates of HBsAg seroclearance in adults with chronic HBV infection: a systematic review and meta-analysis. Gastroenterology. 2019;156:635-646.e9. https://doi.org/10.1053/j. gastro.2018.10.027.

55. Anderson RT, Choi HSJ, Lenz O, Peters MG, Janssen HLA, Mishra P, et al. Association between seroclearance of hepatitis B surface antigen and long-term clinical outcomes of patients with chronic HBV infection: systematic review and meta-analysis. Clin Gastroenterol Hepatol. 2020. https://doi.org/10.1016/j.cgh.2020. 05.041 . 
56. Singh KP, Crane M, Audsley J, Avihingsanon A, Sasadeusz J, Lewin SR. HIV-hepatitis B virus coinfection: epidemiology, pathogenesis, and treatment. AIDS. 2017;31:2035-52. https://doi.org/ 10.1097/QAD.0000000000001574.

57. Matthews GV, Ali RJ, Avihingsanon A, Amin J, Hammond R, Bowden S, et al. Quantitative HBsAg and HBeAg predict hepatitis B seroconversion after initiation of HAART in HIV-HBV coinfected individuals. PLoS One. 2013;8:e61297. https://doi.org/ 10.1371/journal.pone.0061297.

58. Zoutendijk R, Zaaijer HL, de Vries-Sluijs TEMS, Reijnders JGP, Mulder JW, Kroon FP, et al. Hepatitis B surface antigen declines and clearance during long-term tenofovir therapy in patients coinfected with HBV and HIV. J Infect Dis. 2012;206:974-80. https://doi.org/10.1093/infdis/jis439.

59. Chihota BV, Wandeler G, Chilengi R, Mulenga L, Chung RT, Bhattacharya D, et al. High rates of hepatitis B virus (HBV) functional cure among human immunodeficiency virus-HBV coinfected patients on antiretroviral therapy in Zambia. J Infect Dis. 2020;221: 218-22. https://doi.org/10.1093/infdis/jiz450.

60. Huang Y-S, Sun H-Y, Chang S-Y, Chuang Y-C, Cheng A, Huang $\mathrm{S}-\mathrm{H}$, et al. Long-term virological and serologic responses of chronic hepatitis B virus infection to tenofovir disoproxil fumaratecontaining regimens in patients with HIV and hepatitis B coinfection. Hepatol Int. 2019;13:431-9. https://doi.org/10.1007/s12072019-09953-4.

61. Jaroszewicz J, Reiberger T, Meyer-Olson D, Mauss S, Vogel M, Ingiliz $\mathrm{P}$, et al. Hepatitis $\mathrm{B}$ surface antigen concentrations in patients with HIV/HBV co-infection. PLoS One. 2012;7:e43143. https:// doi.org/10.1371/journal.pone.0043143.

62. Boyd A, Gozlan J, Miailhes P, Lascoux-Combe C, Cam MS-L, Rougier H, et al. Rates and determinants of hepatitis B "e" antigen and hepatitis B surface antigen seroclearance during long-term follow-up of patients coinfected with HIV and hepatitis B virus. AIDS. 2015;29:1963-73. https://doi.org/10.1097/QAD. 0000000000000795

63. Panel on Antiretroviral Guidelines for Adults and Adolescents. Guidelines for the use of antiretroviral agents in adults and adolescents with HIV. Department of Health and Human Services. http:// aidsinfo.nih.gov/contentfiles/lvguidelines/AdultandAdolescentGL. pdf (accessed Jul 3, 2020).

64. Walker M, El-Serag HB, Sada Y, Mittal S, Ying J, Duan Z, et al. Cirrhosis is under-recognised in patients subsequently diagnosed with hepatocellular cancer. Aliment Pharmacol Ther. 2016;43: 621-30. https://doi.org/10.1111/apt.13505.

65. Ghany MG. Current treatment guidelines of chronic hepatitis B: the role of nucleos(t)ide analogues and peginterferon. Best Pract Res Clin Gastroenterol. 2017;31:299-309. https://doi.org/10.1016/j. bpg.2017.04.012.
66. Li J, Gordon SC, Rupp LB, Zhang T, Boscarino JA, Vijayadeva V, et al. The validity of serum markers for fibrosis staging in chronic hepatitis B and C. J Viral Hepat. 2014;21:930-7. https://doi.org/10. 1111/jvh. 12224

67. Kim WR, Berg T, Asselah T, Flisiak R, Fung S, Gordon SC, et al. Evaluation of APRI and FIB-4 scoring systems for non-invasive assessment of hepatic fibrosis in chronic hepatitis B patients. J Hepatol. 2016;64:773-80. https://doi.org/10.1016/j.jhep.2015.11. 012.

68. Sterling RK, King WC, Wahed AS, Kleiner DE, Khalili M, Sulkowski M, et al. Evaluating noninvasive markers to identify advanced fibrosis by liver biopsy in HBV/HIV co-infected adults. Hepatology. 2020;71:411-21. https://doi.org/10.1002/hep.30825.

69. Robbins HA, Shiels MS, Pfeiffer RM, Engels EA. Epidemiologic contributions to recent cancer trends among HIV-infected people in the United States. AIDS. 2014;28:881-90. https://doi.org/10.1097/ QAD.0000000000000163.

70. Sahasrabuddhe VV, Shiels MS, McGlynn KA, Engels EA. The risk of hepatocellular carcinoma among individuals with acquired immunodeficiency syndrome in the United States. Cancer. 2012;118: 6226-33. https://doi.org/10.1002/cncr.27694.

71. Engels EA, Yanik EL, Wheeler W, Gill MJ, Shiels MS, Dubrow R, et al. Cancer-attributable mortality among people with treated human immunodeficiency virus infection in North America. Clin Infect Dis. 2017;65:636-43. https://doi.org/10.1093/cid/cix392.

72. Bräu N, Fox RK, Xiao P, Marks K, Naqvi Z, Taylor LE, et al. Presentation and outcome of hepatocellular carcinoma in HIVinfected patients: a U.S.-Canadian multicenter study. J Hepatol. 2007;47:527-37. https://doi.org/10.1016/j.jhep.2007.06.010.

73. Berretta M, Garlassi E, Cacopardo B, Cappellani A, Guaraldi G, Cocchi S, et al. Hepatocellular carcinoma in HIV-infected patients: check early, treat hard. Oncologist. 2011;16:1258-69. https://doi. org/10.1634/theoncologist.2010-0400.

74. Torgersen J, Kallan MJ, Carbonari DM, Park LS, Mehta RL, D'Addeo K, et al. HIV RNA, CD4+ percentage, and risk of hepatocellular carcinoma by cirrhosis status. J Natl Cancer Inst. 2019;112:747-55. https://doi.org/10.1093/jnci/djz214.

75. Lin C-L, Kao J-H. Risk stratification for hepatitis B virus related hepatocellular carcinoma. J Gastroenterol Hepatol. 2013;28:10-7. https://doi.org/10.1111/jgh.12010.

76. Merchante N, Rodríguez-Fernández M, Pineda JA. Screening for hepatocellular carcinoma in HIV-infected patients: current evidence and controversies. Curr HIV/AIDS Rep. 2020;17:6-17. https://doi. org/10.1007/s11904-019-00475-0.

Publisher's Note Springer Nature remains neutral with regard to jurisdictional claims in published maps and institutional affiliations. 